\title{
Isolated unilateral lower motor neuron facial palsy as the presenting feature of Guillain Barre Syndrome in a child
}

\author{
*V P Sinhabahu ${ }^{1}, \mathrm{~S}$ Wijesekara ${ }^{2}$ \\ Sri Lanka Journal of Child Health, 2016; 45(1): 48-49 \\ DOI: http://dx.doi.org/10.4038/sljch.v45i1.8087 \\ (Key words: Guillain Barre Syndrome; unilateral facial palsy)
}

We report a rare presentation of a child with unilateral facial palsy that progressed to full blown Guillain Barre Syndrome (GBS) within the next three days.

\section{Case report}

An 11 year old girl presented with inability to close the left eye and water drooling from left corner of the mouth while drinking for one day. There was no history of preceding illness or trauma. Examination revealed isolated lower motor neuron type left facial nerve palsy grade $\mathrm{V}$ according to the HouseBrackmann grading system ${ }^{1}$. The rest of the neurological examination was normal with intact sensation. She was treated with oral acyclovir and prednisolone and was referred for physiotherapy. On day 3 of the illness, she developed difficulty in getting up from the squatting position. Examination revealed bilateral weakness of lower limbs (Grade 3) with absent ankle jerks along with the left sided lower motor neuron facial nerve palsy noted three days back. No sensory deficits were noted. During the next 24 hours, weakness progressed to involve both upper limbs and the right facial nerve (HouseBrackmann grade III). External ophthalmoplegia was not noted. Nerve conduction study done on the $4^{\text {th }}$ day gave the following results as shown in Table 1.

Table 1: Results of nerve conduction study

\begin{tabular}{|l|c|c|c|c|}
\hline & Terminal latency & Nerve conduction velocity & F wave & Comment \\
\hline Right median nerve & 6.46 & 67.4 & -27.9 & Conduction block + \\
\hline Right ulnar nerve & 64.4 & 58.4 & -34.9 & \\
\hline $\begin{array}{l}\text { Right common } \\
\text { peroneal nerve }\end{array}$ & 5.98 & 34.0 & Not recorded & Conduction block + \\
\hline
\end{tabular}

Delayed terminal latency (TLC), delayed F waves and delayed nerve conduction velocity (NCV) in the lower limbs were in favour of the diagnosis of GBS. Child was given intravenous immunoglobulin 0.4 $\mathrm{g} / \mathrm{kg}$ daily for five days. Her vital parameters were monitored and were normal during the hospital stay. She recovered without any residual paralysis. Lumbar puncture was performed on the $10^{\text {th }}$ day after the

${ }^{1}$ Registrar in Paediatrics, Professorial Paediatric unit, ${ }^{2}$ Senior Lecturer in Paediatrics and Consultant Paediatric Neurologist, Colombo South Teaching Hospital, Sri Lanka

*Correspondence: sinbad.lk@gmail.com

(Received on 4 September 2014: Accepted after revision on 24 October 2014)

The authors declare that there are no conflicts of interest

Personal funding was used for this project.

Open Access Article published under the Creative Commons Attribution CC-BY (CC) onset of lower limb weakness and revealed cytoalbuminological dissociation with 10 lymphocytes/cu $\mathrm{mm}$ and cerebrospinal fluid (CSF) protein of $68.7 \mathrm{mg} / \mathrm{dl}$. Stools samples were sent to the Medical Research Institute according to the national guideline on Acute Flaccid Paralysis and did not yield any enteroviruses including poliovirus. Serum IgM for herpes simplex virus, cytomegalovirus and Epstein Barr virus were negative.

\section{Discussion}

GBS is an acute immune-mediated polyneuropathy with strong associations with antecedent infections. Several variant forms of GBS have been described, including acute inflammatory demyelinating polyneuropathy, acute motor axonal neuropathy, acute motor-sensory axonal neuropathy, and sensory $\mathrm{GBS}^{2}$. Bilateral facial nerve palsy is the most common pattern of cranial nerve involvement in $\mathrm{GBS}^{3}$. Unilateral facial paralysis is a common clinical entity where the majority are due to idiopathic or Bell's palsy ${ }^{4}$. However, unilateral facial palsy, 
although uncommon, can be seen in $\mathrm{GBS}^{5,6}$. Unilateral facial palsy as the presenting feature of GBS has been found in 2 previous case reports ${ }^{6}$.

In the first case, a previously well 5 year old girl presented with acute bifrontal headache and isolated left lower motor neuron facial nerve palsy following a one week history of mild coryzal symptoms ${ }^{6}$. Initial assessment revealed a persistently elevated blood pressure (BP) of $130 / 100 \mathrm{mmHg}$. Cardiovascular examination revealed a normal heart, equal upper and lower limb pulses and no decrease in lower limb BP. Cranial nerve examination revealed a left lower motor neuron seventh nerve palsy. Fundoscopy, other cranial nerves and motor system examinations were normal. Her BP was slowly lowered to the 90th percentile for age and gender with small doses of nifedipine. Over the next 48 hours she developed features of GBS with typical CSF findings. A diagnosis of GBS with secondary hypertension was made. Intravenous immunoglobulin was given (total dose of $2 \mathrm{~g} / \mathrm{kg}$ ) on days 3 and 4 from presentation, with a resultant halt in the progression of neurological disease. Peripheral nerve conduction studies on day 5 confirmed a demyelinating polyradiculoneuropathy ${ }^{6}$.

In the second case, a 3 year old girl presented with an acute left lower motor neuron facial nerve palsy ${ }^{6}$. She had been in good health apart from having a coryzal illness, 1 month previously. Her BP was elevated at 126/110 mmHg. As well as the left facial palsy, she manifested gait ataxia, proximal weakness and absent lower limb deep tendon reflexes. CSF showed cytoalbuminological dissociation and nerve conduction studies demonstrated a demyelinating polyneuropathy consistent with GBS. Intravenous immunoglobulin (total dose of $2 \mathrm{~g} / \mathrm{kg}$ ) was administered over 2 days with subsequent clinical improvement. BP control was achieved with nifedipine and clonidine.

\section{References}

1. House J W, Brackmann D E. Facial nerve grading system. Otolaryngology and Head Neck Surgery 1985; 93: 146-7.

PMid: 3921901
2. Kamihiro N, Higashigawa M, Yamamoto T, Yoshino A, Sakata K, Nashida Y, et al. Acute motor-sensory axonal Guillain-Barré syndrome with unilateral facial nerve paralysis after rotavirus gastroenteritis in a 2year-old boy. Journal of Infection and Chemotherapy 2012; 18:119-23. http://dx.doi.org/10.1007/s10156-011-0300-8 PMid: 21915637

3. Narayanan RP, James N, Ramachandran K, Jaramillo MJ. Guillain-Barré syndrome presenting with bilateral facial nerve paralysis: a case report. Cases Journal 2008; 1: 379. Available from:

http://www.ncbi.nlm.nih.gov/pmc/articles/P MC2627812/

http://dx.doi.org/10.1186/1757-1626-1-379

PMid: 19063750 PMCid: PMC 2627812

4. Alaani A, Hogg R, Saravanappa N, Irving RM. An analysis of diagnostic delay in unilateral facial paralysis. Journal of Laryngology and Otology 2005; 119(3): 1848. http://dx.doi.org/10.1186/1757-1626-1-379 PMid: 19063750 PMCid: PMC2627812

5. Verma R, Chaudhari TS, Giri P. Unilateral facial palsy in Guillain-Barre syndrome (GBS): a rare occurrence. British Medical Journal Case Reports, 2012. October 18, 2012. Available from:

http://www.ncbi.nlm.nih.gov/pubmed/230872 83

6. Smith N, Grattan-Smith P, Andrews PI, Kainer G. Acquired facial palsy with hypertension secondary to Guillain-Barre syndrome. Journal of Paediatrics and Child Health 2010; 46(3): 125-7.

http://dx.doi.org/10.1111/j.14401754.2009.01 650.x

PMid: 20158600 